10 Siegel S. Nonparametric statistics for the behavioural sciences. New York McGraw-Hill, 1956.

11 Fleiss JL. Statistical methods for rates and proportions. 2nd ed. New York $\mathrm{J}$ Wiley, 1981.

12 Cotes JE. Lung function. Assessment and application in medicine. Oxford: Blackwell, 1979.

${ }^{13}$ Krumholz RA, Hendrick EC. Pulmonary function differences in normal smoking and nonsmoking, middle-aged white-collar workers. Am Rev Respir Dis 1973;107:225-30.

${ }^{14}$ Dobbs J, Marsh A. Smoking among secondary school children: office of population census and surveys. London: HMSO, 1983.
${ }^{15}$ Murray M, Swan AV, Enock C, Johnson MRD, Banks DH, Reid DJ. The effectiveness of the Health Education Council's "My Body" school health education project. Health Educ $\mathcal{F} 1982 ; 41$ :126-30.

${ }^{16} \mathrm{McKennell}$ AC. Bias in the reported incidence of smoking by children. Int 7 Epidemiol 1980;9:167-77.

17 Tashkin DP, Clark VA, Coulson $\mathrm{AH}$, et al. Comparison of lung function in young nonsmokers and smokers before and after initiation of the smoking habit. Am Rev Respir Dis 1983;128:12-6.

(Accepted 10 January 1984)

\title{
Comparison of regimens of treatment with sodium stibogluconate in kala-azar
}

\author{
C P THAKUR, MAHENDRA KUMAR, SATIS KUMAR SINGH, DILIP SHARMA, \\ UMA SHANKER PRASAD, RAMA SHRAY PRASAD SINGH, P S DHAWAN, VIJAY ACHARI
}

\begin{abstract}
One hundred and twenty six patients with kala-azar (visceral leishmaniasis) were allocated at random to one of two groups for treatment with sodium stibogluconate. One group was treated for 20 days; in the other group the patients were assessed after 20 days' treatment and treatment was continued if necessary. Both groups were followed up for six months. There was no significant difference in symptomatic outcome between the two groups at 20 days. At six months eight of the patients in the group treated for 20 days had relapsed and 54 were cured. Of the group given more than 20 days' treatment if necessary, 62 were cured and none had relapsed (12 required more than 20 days' treatment). This difference between the two groups was significant. One patient in each group did not respond to sodium stibogluconate, but both were cured with pentamidine. Altogether 104 patients were cured after 20 days' treatment; 20 , including the eight who relapsed, were cured after more than 20 days' treatment. There was no significant difference between the two groups in the side effects of the drug, which were minor. The longer courses of treatment ( 50 days in one patient) were well tolerated.

It is suggested that the traditional six day course of treatment with sodium stibogluconate for kala-azar is grossly inadequate and that a longer course is required to prevent relapse.
\end{abstract}

Patna Medical College Hospital, Patna 800004, India

C P THAKUR, MD, FRCP, professor of medicine

MAHENDRA KUMAR, MD, assistant professor

SATIS KUMAR SINGH, MD, resident medical officer

DILIP SHARMA, MB, BS, postgraduate student

UMA SHANKER PRASAD, MB, BS, postgraduate student

RAMA SHRAY PRASAD SINGH, MB, BS, postgraduate student

P S DHAWAN, MB, BS, postgraduate student

VIJAY ACHARI, MB, BS, senior house physician

Correspondence and requests for reprints to: Professor C P Thakur.

\section{Introduction}

In the 1970s Bihar province in India experienced a massive epidemic of kala-azar (visceral leishmaniasis), and the disease is still endemic in some areas. Out of the 400000 new cases of leishmaniasis in the world in 1977,1 a quarter occurred in Bihar. ${ }^{2}$ Sodium stibogluconate was used as a first line drug during this epidemic. Manson-Bahr's regimen of six days' treatment with sodium stibogluconate, ${ }^{4}$ still advocated in current editions of most textbooks, ${ }^{5-8}$ was the standard treatment in India.

A committee of Indian experts suggested that two courses of sodium stibogluconate lasting for 10 days each and interrupted by a break of 10 days should be adequate to treat Indian kala-azar. ${ }^{2}$ This was a modified version of Manson-Bahr's regimen of treatment for Kenyan kala-azar. ${ }^{9}$ We had found Manson-Bahr's regimen for Indian kala-azar grossly inadequate, and even with the regimen suggested by the committee of Indian experts the incidence of relapse was high. ${ }^{1011}$ We started to give the drug continuously for 20 days, or even longer in some cases, and the incidence of relapse $(0.5 \%)$ was almost negligible. ${ }^{12}$ This encouraged us to compare in a randomised trial the efficacy, safety, and desirability of giving the drug for 20 days, or longer if necessary. We report the outcome of that trial.

\section{Patients and methods}

We undertook this trial to see whether treatment with antimony for 20 days, or longer if necessary, was effective and could be tolerated by Indian patients with kala-azar. A subsidiary aim was to confirm that it is not necessary to give an initial dose of 1 or $2 \mathrm{ml}$ to test for hypersensitivity. On the basis of previous experience, assuming the incidences of drop out and of spontaneous cure to be $0 \%$ and the incidence of cure with the standard treatment to be $70 \%$, and with the difference in the incidence of cure between the standard treatment and the new treatment expected to be $20 \%$, we used a sample size of at least $60 .{ }^{13}$

The study was conducted from January 1981 to November 1982. All patients at this hospital with kala-azar, confirmed by the finding of amastigotes of leishmania (figure) in smears of bone marrow or spleen stained with Giemsa, were included in the study. Patients were excluded if they had haemoglobin concentrations below $3 \mathrm{~g} / \mathrm{dl}$; had complications such as pneumonia, jaundice, tuberculosis, or renal disease; or had received treatment with antimony or pentamidine for kala-azar before coming to this hospital. A total of 126 patients (104 men and 22 women (ratio 4.4:1)) were entered into the trial. Equal numbers of men and women were randomly allocated to two 
treatment groups (see below). Only eight patients in the first group and six in the second were aged under 18.

The clinical state of each patient was thoroughly assessed before the start of treatment. The duration of illness was noted. The spleen was measured in the anterior axillary line from the costal margin to its tip and the liver in the midclavicular line from the costal margin to its margin. Patients' weights were noted. Total and differential counts of white cells, haemoglobin and serum protein concentrations, and serum alanine transaminase and aspartate transaminase activities were measured. A urine examination, chest $x$ ray examination, and electrocardiography were also done in each patient.

\section{REGIMENS OF TREATMENT}

Patients aged 12 or more in both groups were given sodium stibogluconate $(100 \mathrm{mg}$ antimony $/ \mathrm{ml}) 6 \mathrm{ml}$ daily intramuscularly in the buttocks. Patients aged below 12 received $20 \mathrm{mg}$ antimony $/ \mathrm{kg}$ body weight/day intramuscularly.

In 63 patients (group 1) the drug was stopped after 20 days. Patients were then assessed clinically: bone marrow or splenic aspiration was repeated and total and differential white cell counts,

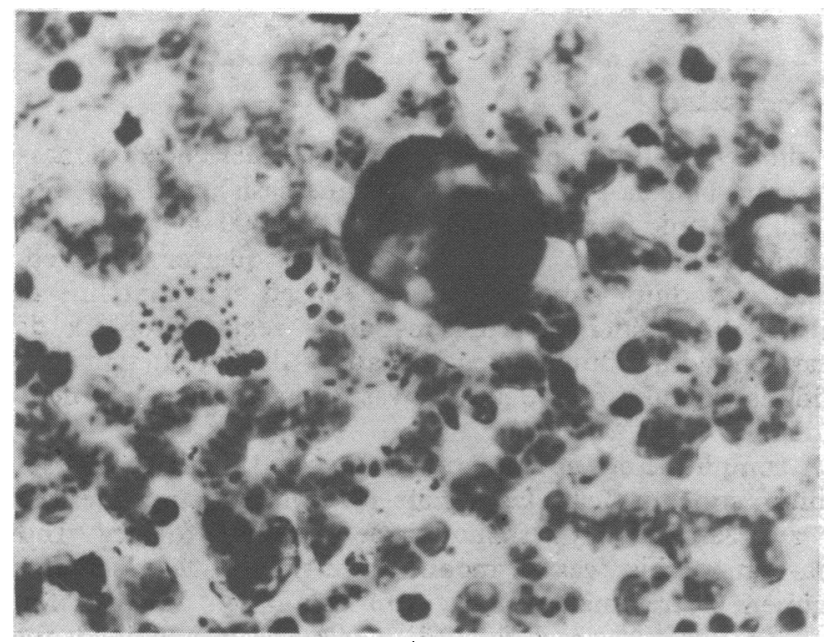

Leishman-Donovan bodies inside and outside macrophages in smear of aspirate of bone marrow (Giemsa stain) $\times 1000$.

haemoglobin concentration, and serum alanine transaminase and aspartate transaminase activities were measured. Electrocardiography and urine examination were done, and patients were asked to attend for follow up irrespective of the presence or absence of parasites on smear examination. Patients were asked to report immediately if they developed a fever. Patients who did not respond to 20 days of treatment with sodium stibogluconate were labelled unresponsive to antimony and treated with 15 injections of pentamidine $4 \mathrm{mg} / \mathrm{kg}$ body weight intramuscularly on alternate days.

The remaining 63 patients (group 2) were similarly assessed after 20 days of treatment with sodium stibogluconate, but if parasites were found on smear examination or if the clinical response was slow the drug was continued for at least another 10 days. After the 30 th or 40 th day of treatment patients were assessed for further treatment as in group 1 and were asked to attend for follow up. Patients in group 1 who relapsed were subsequently treated according to the regimen used in group 2.

All the patients were examined daily under blind conditions by one of us, who noted the responses to treatment. Weekly measurements of body weight, splenic size, haemoglobin concentration, leucocyte count, and temperature were recorded. Patients were asked to describe any toxic effects such as anorexia, rashes, muscle pain, and hypersensitivity reactions. Initial cure was indicated by the return of the temperature to normal, a decrease in the size of the spleen, and an improvement in general condition. Parasitological cure was indicated by the absence of parasites on smear examination after treatment. Apparent cure was taken as clinical cure combined with parasitological cure. Complete cure was taken as clinical and parasitological cure with no relapse during six months of follow up.
FOLLOW UP

The patients were followed up every month for six months and were called to each follow up by card or messenger. A further card or messenger was sent if a patient did not turn up on the correct day. At each follow up patients were examined and routine investigations done. At the final follow up bone marrow aspiration was done.

\section{DATA ANALYSIS}

Statistical analysis was by Fisher's exact test with Armitage's modification for two tailed tests. ${ }^{14}$

\section{Results}

Initial clinical findings-The two groups were comparable (table I). The main clinical features were intermittent fever, loss of appetite, shivering or rigor, splenohepatomegaly, no lymphadenopathy, leucopenia with monocytosis, and anaemia.

After 20 days of treatment there was no difference in the incidence of initial cure, parasitological cure, or apparent cure between the two groups (table II). One patient from each group did not respond to antimony but improved with pentamidine.

At six month' follow up 62 patients in group 2 and 54 in group 1 were cured. One patient in each group had not responded to treatment. None of the patients in group 2 but eight of those in group 1 had relapsed: two within 15 days, four within two months, and two within three months. They were all subsequently cured with treatment lasting for more than $\mathbf{2 0}$ days (given for $\mathbf{4 0}$ days after relapse in five cases and for 30 days in three). Twelve of the patients in group 2 had needed more than 20 days' treatment: eight had been treated for 30 days, three for 40 , and one for 50 . All 12 patients were slow responders (table III). Altogether, 54 patients in group 1 and 50 in group $2\left(83^{\circ}\right.$, of the total) were cured after 20 days' treatment; and 20 patients $\left(16^{\circ}{ }_{0}\right)$ (12 in group 2 and the eight in group 1 who relapsed) were cured after treatment lasting for more than 20 days. Two patients were cured with pentamidine.

Side effects and tolerance-No side effects developed that were severe enough to necessitate withdrawal of treatment (table IV). No patients developed a hypersensitivity reaction. All the patients who were given antimony for more than 20 days, including a boy who was given it for $\mathbf{5 0}$ days, tolerated it well.

TABLE I-Initial clinical findings in two groups of patients with kala-azar

\begin{tabular}{|c|c|c|}
\hline & $\begin{array}{c}\text { Group 1 } \\
\text { (20 days' } \\
\text { treatment) }\end{array}$ & $\begin{array}{c}\text { Group } 2 \\
\left(\begin{array}{c}20 \text { days } \\
\text { treatment })\end{array}\right.\end{array}$ \\
\hline No of men & 52 & 52 \\
\hline No of women & 11 & 11 \\
\hline No of patients aged 18 & & 8 \\
\hline $\begin{array}{l}\text { Mean age (median) (range) (years) } \\
\text { Mean (SD) duration of symptoms (months) }\end{array}$ & $26 \cdot 8(19 \cdot 5)(11-40)$ & $28 \cdot 2(18)(9-42)$ \\
\hline \multicolumn{3}{|l|}{ No of patients with: } \\
\hline Intermittent fever & 63 & 63 \\
\hline Shivering or rigor & 42 & 36 \\
\hline Loss of appetite & 44 & 40 \\
\hline Pigmentation of skin & 28 & 34 \\
\hline Lymphadenopathy & 0 & 0 \\
\hline Mean (SD) splenic size $(\mathrm{cm})$ & $11 \cdot 2 \quad(4 \cdot 2)$ & $10 \cdot 8 \quad(4 \cdot 6)$ \\
\hline $\begin{array}{l}\text { Mean (SD) haemoglobin concentration } \\
\left(\mathbf{g}^{\prime} \mathrm{dl}\right)\end{array}$ & $7 \cdot 4 \quad(2 \cdot 6)$ & $7 \cdot 6 \quad(2 \cdot 4)$ \\
\hline Mean (SD) white cell count $\left(\times 10^{y / 1}\right)$ & $4 \cdot 2 \quad(1 \cdot 6)$ & $3.8(1 \cdot 2)$ \\
\hline
\end{tabular}

TABLE II-Outcome of 20 days' treatment in both groups (figures are numbers of patients)

\begin{tabular}{lcc}
\hline & Group 1 & Group 2 \\
\hline Initial cure & 62 & 62 \\
No response* & 1 & 1 \\
Parasitological curet & 56 & 54 \\
Apparent cure + & 53 & 53 \\
Parasites present in aspirates of bonc & 7 & 10 \\
$\quad$ marrow\$ & 8 & 12 \\
\hline
\end{tabular}

* No response to 20 days of treatment with sodium stibogluconate.

*Absence of parasites in aspirate of bone marrow or spleen.

+Absence of parasites in aspirate Initial and parasitological cure.
\$Group 1: parasites present in one non-responder, six slow responders, and threc
fast responders; group 2: parasites present in one non-responder, eight slow responders, and one fast responder. 
TABLE III-Clinical findings in fast and slow responders from both groups after 20 days of treatment

\begin{tabular}{lcc}
\hline & $\begin{array}{c}\text { Fast responders } \\
(\mathrm{n}=104)\end{array}$ & $\begin{array}{c}\text { Slow responders* } \\
(\mathrm{n}=20)\end{array}$ \\
\hline Mean febrile period (days) & $4 \cdot 5$ & $8 \cdot 2$ \\
No with splenic size: & 0 & 20 \\
$\quad 3 \mathrm{~cm}$ & 54 & 0 \\
$\quad \begin{array}{l}3 \mathrm{~cm} \\
\text { No with impalpable spleen } \\
\text { exam parasites present on smear }\end{array}$ & 50 & 0 \\
\hline
\end{tabular}

*Twelve patients treated for more than 20 days (group 2) and eight patients given only 20 days' treatment (group 1) who relapsed.

TABLE IV - Side effects of treatment with sodium stibogluconate

\begin{tabular}{lcc}
\multicolumn{1}{c}{ Side effects } & Group 1 & Group 2 \\
\hline Pain at site of injection & 6 & 8 \\
Feeling of warmth & 12 & 11 \\
Swelling at site of injection but no abscess & 2 & 1 \\
\hline
\end{tabular}

\section{Discussion}

This study shows that 20 days of treatment with sodium stibogluconate is well tolerated and effective in many patients with kala-azar; continuing the drug for longer results in cure in most of the remaining patients. We made several changes in the recommended regimen of treatment for Indian kala-azar: the rest period between the two courses was abolished; the drug was used for longer than ever before in India; and the initial test for hypersensitivity was not done. None of the patients in the group given more than 20 days' treatment if necessary (group 2) relapsed, and the incidence of cure in this group was $98 \%$. Of the patients in the group initially given only 20 days' treatment (group 1), eight $(13 \%)$ relapsed and $54\left(86^{\prime \prime}\right)$ were cured. This difference in the incidence of cure between the two groups was significant $(p=0.02)$.

Sen Gupta thought that sodium stibogluconate was a much weaker drug than urea stibamine or methylglucamine antimoniates, ${ }^{15}$ and the incidence of relapse in his series of patients varied from 10 to $15 \% .^{1011} \mathrm{He}$ administered 15 injections of sodium stibogluconate on alternate days. This different regimen might have been the cause of the higher incidence of relapse in his series. Anabwani et al showed that patients who had relapsed responded to a higher dosage given for a longer period and that the incidence of relapse was negligible when sodium stibogluconate was continued for a longer period in patients who responded slowly. ${ }^{16}$ These slow responders when compared with fast responders had longer periods of fever, and parasites persisted for longer in their splenic aspirates. Their spleen also remained larger than $5 \mathrm{~cm}$ after 20 days of treatment. At a recent workshop held in Nairobi under the auspices of the World Health Organisation the dosage recommended for general use was $20 \mathrm{mg}$ sodium stibogluconate $\mathrm{mg} / \mathrm{kg}$ body weight (maximum $850 \mathrm{mg}$ ) daily for 20 days; the same dosage but given for 40 days was recommended for patients who have relapsed. ${ }^{12}$ Our study suggests that the initial duration of treatment should be based on certain variables if relapse is to be minimised. One of the main objectives of the treatment of visceral leishmaniasis defined in Nairobi was to prevent relapse ${ }^{12}$ : relapse demoralises patients, predisposing them to another relapse and making them unresponsive to antimony. ${ }^{1:}$

Two patients were unresponsive to sodium stibogluconate. They did not give a history of having taken antimony before and were therefore labelled as cases of primary unresponsiveness. It might be argued that their treatment should have been prolonged beyond 20 days, but by then their conditions had started to deteriorate; in such cases pentamidine was started, to which both patients responded. Unresponsiveness to antimony may arise during the course of treatment and is then called secondary unresponsiveness. A third type of unresponsiveness, relative unresponsiveness, occurs when patients respond only to higher dosages of the drug given for longer periods. In our experience, and in that of other workers, ${ }^{16}$ patients labelled as unresponsive improve when the dose of sodium stibogluconate is increased and the duration of treatment prolonged. We have found that a rest period between two courses of treatment encourages unresponsiveness. Fortunately in this series there were only two cases of primary unresponsiveness and none of secondary or relative unresponsiveness. Administration of the drug for longer periods to slow responders might be the reason for this. The drug did not produce any major side effects, but patients complained of pain at the site of injection due to the large doses given. There was no difference in side effects between the two groups. We had feared when the trial was started that the drug might produce serious side effects in patients receiving it for more than 20 days, but they tolerated it well. Neither in this series nor in our previous series of 750 patients $^{12}$ did we come across any case of hypersensitivity to antimony.

We suggest that sodium stibogluconate should be given to Indian patients with kala-azar for more than 20 days if this is indicated without any rest period between courses. A trial is needed to assess the efficacy of higher dosages given for shorter periods.

We thank Mr Arun Kumar Sinha, lecturer, department of statistics, Patna University, for his advice; Professor A K Gupta, professor of pathology, for laboratory help; Mr Ram Janam Sharma, laboratory technician, for his help; and Mr C P Singh for typing the manuscript.

\section{References}

1 Scientific Working Group of the UNDP/World Bank/WHO. Third annual report. Special programme for research and training in tropical diseases. Geneva: World Health Organisation, 1980.

${ }^{2}$ Anonymous. Proceedings of the meeting of an expert group on kala-azar held at Indian Council of Medical Research headquarters on 9 September 1977. New Delhi: Indian Council of Medical Research, 1977.

3 Thakur CP, Kumar M, Pathak PK. Kala-azar hits again. $\mathcal{F}$ Trop Med Hyg $1981 ; 84: 271-6$.

- Wilcocks C, Manson-Bahr PEC, eds. Manson's tropical diseases. London Baillière Tindall, 1972:117-47.

${ }^{5}$ Woodruff AW. Leishmaniasis. In: Sir B Scott, ed. Price's textbook of the practice of medicine. Oxford: Oxford University Press, 1978:188-93.

${ }^{6}$ Plorde JJ. Leishmaniasis. In: Isselbacher KJ, Adams RD, Braunwald E, Petersdorf RG, Wilson JD, eds. Harrison's principles of internal medicine. 9th ed. New York: McGraw-Hill, 1980:873-6.

'Wright FJ. Leishmaniasis. In: Fleming PR, ed. Davidson's principles and practice of medicine. Edinburgh: Churchill Livingstone, 1980:815-8.

${ }^{8}$ Bryceson ADM. Leishmaniasis. In: Wyngaarden JB, Smith LH Jr, eds. Cecil textbook of medicine. Philadelphia: W B Saunders, 1982:1731-4.

${ }^{9}$ Manson-Bahr PEC. East African kala-azar with special reference to the pathology, prophylaxis and treatment. Trans $R$ Soc Med Hyg 1959;53: 123-37.

10 Gupta PCS. Leishmaniasis. In: Banergee JC, Bhattachrya PB, eds. $A$ handbook of tropical diseases. Calcutta: Academic Publishers, 1960:103-40.

1 Gupta PCS. Chemotherapy of leishmanial diseases: a resumé of recent researches. Indian Medical Gazette 1953;88:20-35.

12 Scientific Working Group of the UNDP/World Bank/WHO. Fourth annual report. Special programme for research and training in tropical diseases. Report of the informal meeting on the chemotherapy of visceral leishmaniasis. Geneva: World Health Organisation, 1982. (TOR Chem LEISH/VL/82.3.)

${ }^{13}$ Dowd JE. Health statistical methodology. In: Report of the workshop on the chemotherapy of mucocutanous leishmaniasis. Geneva: World Health Organisation, 1979. (TDR/LEISH/MCL 793.)

14 Swinscow TDV. Statistics at square one. London: British Medical Association, 1980:31, 54

1.5 Gupta PCS. Return of kala-azar. F Indian Med Assoc 1975;65:89-90.

${ }_{16}$ Anabwani GM, Ngira JA, Dimiti G, Bryceson ADM. Comparison of two dosage schedules of sodium stibogluconate in the treatment of visceral leishmaniasis in Kenya. Lancet 1983;i:210-2, 3.

17 Wijegs DJB. A ten years' study of kala-azar in Tharaka (Meru District, Kenya). Part II. Relapses. East Afr Med f 1971;48:551-8.

(Accepted 22 December 1983) 